\title{
Fatty acid, tocopherol, mineral composition, total phenolic, flavonoid and thymoquinone content, and antioxidant potential of Nigella stellaris
}

\author{
Sibel Silahtaroğlu a, Serife Selma Uras Güngör a, Ahmet İlçim b, and Gamze Kökdil a,* \\ a Department of Pharmacognosy, Faculty of Pharmacy, Mersin University, Yenisehir Campus, 33169 Mersin, Turkey \\ b Department of Biology, Faculty of Arts and Science, Mustafa Kemal University, 31000, Antakya, Hatay, Turkey \\ *Corresponding author at: Department of Pharmacognosy, Faculty of Pharmacy, Mersin University, Yenisehir Campus, 33169 Mersin, Turkey. \\ Tel.: +90.324.3413021. Fax:+90.324.3413022.E-mail address: gkokdil@gmail.com (G. Kökdil).
}

\section{ARTICLE INFORMATION}

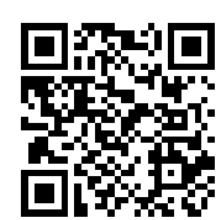

DOI: $10.5155 /$ eurjchem.5.2.263-266.1006

Received: 26 November 2013

Received in revised form: 05 January 2014

Accepted: 05 January 2014

Online: 30 June 2014

\section{KEYWORDS}

Minerals

Fatty acid

N. stellaris

Tocopherols

Antioxidant activity

Total phenol and flavonoids

\section{Introduction}

The genus Nigella L. (Ranunculaceae) includes about 22 species distributed from the Mediterranean regions to West Asia [1-3]. Some Nigella species especially $N$. sativa have been used traditionally in Arabian countries, Indian subcontinent and Europe for culinary and medicinal purposes. The seeds of $N$. sativa (black seed/ black cumin) are used as natural remedy for many ailments including asthma, cough, bronchitis, headache, rheumatism, hypertension, fever and influenza $[4,5]$. Black cumin has been extensively studied phytochemically and pharmacologically $[5,6]$ and it was known that the plant contain fixed and volatile oil, quinonic compounds, vitamins, phenolic compounds, alkaloids, saponins, sterols, minerals, aminoacids, proteins and carbonhydrates [6-9]. Recent studies showed that N.sativa have antimicrobial, anticestode, antitumor, antidiabetic, antioxidant, antiallergic, anti-inflammatory, immunomodulatory, antiaflatoxine, spasmolytic, bronchodilator, hypocholesterolemic, hypotensive, hepatoprotective, antinociceptive, neuroprotective and anticonvulsant effects [5-12].

$N$. sativa seeds have been intensively investigated to determine its nutritional and therapeutic value whereas little information is known concerning the chemical composition and biological activity about other Nigella species [13-17]. The genus Nigella comprises about 15 taxa in Turkey $[2,3,18]$. $N$. stellaris is one of these taxa, which grows in East Mediterranean region. It is an annual plant grows to $5-20 \mathrm{~cm}$ tall with laciniae linear-setaceous leaf, lavender-blue sepals, follicles acutely keeled, styles longer than the fused follicles, spreading horizontally to form a rigid star. This species has not been studied phytochemically and pharmacologically. The aim of the present study was to investigate $N$. stellaris seeds in detail chemically for possible nutritional value. In this study, the total phenolic and flavonoid content and its antioxidant activity of the methanolic extracts of $N$. stellaris seed and herbs were also tested.

\section{Experimental}

\subsection{Plant material}

Nigella stellaris Boiss. was collected from Southern Turkey (C6 Maraş: Avşar village, 580-600 m, fields) in June 2008 by one of the authors (A. İlçim). Voucher specimen was deposited in the Herbarium of the Department of Biology, Faculty of Arts and Sciences, Kahramanmaraş Sütçü İmam University (Ahmet İlçim $1762 \mathrm{KSUH}$ ) and identified by Dr. Ahmet İLçiM (Department of Biology, Faculty of Arts and Sciences, Mustafa Kemal University, Antakya-Hatay, Turkey) 


\subsection{Reagents and chemicals}

All chemicals were analytical-reagent grade and obtained from the following sources: Methanol, $n$-hexane and FolinCiocalteu's phenol reagent were purchased from Merck (Darmstadt, Germany). 2,2-Diphenyl-1-picrylhydrazyl (DPPH), butylated hydroxyanisole (BHA), gallic acid and thymoquinone were obtained from Sigma Chemical Company (Sigma, MO, USA). Rutin was obtained from Fluka Chemie (Buchs, Switzerland).

\subsection{Extraction procedure}

The seeds were powdered mechanically and extracted with $n$-hexane for $6 \mathrm{~h}$ in a Soxhlet apparatus. Removal of the solvent under reduced pressure gave the fixed oil. The fatty acid content of the fixed oil was investigated by GC and GC-MS analysis of their methyl esters. Oil $(0.5 \mathrm{~g})$ was dissolved in 10 $\mathrm{mL} n$-hexane in a centrifuged tube and $2 \mathrm{~mL} 2 \mathrm{M}$ methanolic $\mathrm{KOH}$ was added. The mixture was shaken for $2 \mathrm{~min}$ and centrifuged at $4000 \mathrm{rpm}$ for $15 \mathrm{~min}$. The upper layer was removed, washed with water, and $1 \mathrm{~mL}$ used for analysis [19].

For thymoquinone analysis, a powdered $N$. stellaris seed sample of $0.1 \mathrm{~g}$ was extracted with $10 \mathrm{~mL}$ methanol, vortexed for $1 \mathrm{~min}$ and sonicated for $20 \mathrm{~min}$. After that, it was left overnight in constant rotamix, sonicated for 1 hour and vortexed for $1 \mathrm{~min}$ and centrifuged for $25 \mathrm{~min}$ at $1600 \mathrm{rpm}$. The supernatant phase was transferred to a volumetric flask. The volume was completed to $10 \mathrm{~mL}$ with methanol. An aliquot of $20 \mu \mathrm{L}$ was injected into the HPLC [8].

\subsection{Gas chromatography-mass spectrometry analysis}

Gas chromatography-mass spectrometry (GC-MS) analyses were carried out on an Agilent Technologies $6890 \mathrm{~N}$ Network GC System equipped with a DB-Wax capillary column (60 $\mathrm{m} \times$ $0.25 \mathrm{~mm}, 0.25 \mu \mathrm{m})$ and DB-23 capillary column $(60 \mathrm{~m} \times 0.25$ $\mathrm{mm}, 0.25 \mu \mathrm{m}$ ) and interfaced with an Agilent 5973 Network Mass Selective Detector. The oven temperature was kept at 140 ${ }^{\circ} \mathrm{C}$ for $5 \mathrm{~min}$, programmed to $165^{\circ} \mathrm{C}$ at a rate of $5{ }^{\circ} \mathrm{C} / \mathrm{min}$ and kept at $165^{\circ} \mathrm{C}$ for $10 \mathrm{~min}$, then programmed to $190^{\circ} \mathrm{C}$ at a rate of $5{ }^{\circ} \mathrm{C} / \mathrm{min}$ and kept at $190{ }^{\circ} \mathrm{C}$ for $55 \mathrm{~min}$. The split ratio was 30:1. Transfer line temperature $280^{\circ} \mathrm{C}$; ion source temperature $210{ }^{\circ} \mathrm{C}$; carrier gas helium at a linear velocity of $1.5 \mathrm{~mL} / \mathrm{min}$.; ionization energy $70 \mathrm{eV}$; scan range 15-550 amu. Relative percentage amounts were calculated from the total area under the peaks by the software of the apparatus.

The constituents of the fixed oil were identified by comparison of their GC retention times with those of reference methyl esters of the fatty acid and also by comparison of their mass spectra with published spectra (Famedb23.L: Mass spectral library for FAMEs DB-23 column, NIST02.L mass spectral library).

\subsection{High performance liquid chromatographic analysis}

Tocopherols were analyzed by high-performance liquid chromatography (HPLC) equipped with a FLD ( $E_{x}=295 \mathrm{~nm} \mathrm{Em}$ $=330 \mathrm{~nm})$ and an Atlantis HILIC silica column $(25 \mathrm{~cm} \times 4.6 \mathrm{~mm}$, $5 \mu \mathrm{m}$ ). The fixed oil was used for the analysis. Separation of all tocopherols was based on isocratic elution with the mobile phase hexane containing $4 \% 1$,4-dioxane and $0.04 \%$ acetic acid. The system was operated at a flow-rate of $1 \mathrm{~mL} / \mathrm{min}$. Standard solutions of $\alpha$-tocopherol acetate, $\alpha, \beta, \gamma$ and $\delta$-tocopherols. The tocopherols content of the sample was quantified by the external standard method

Thymoquinone analyses were carried out by RP-HPLC. A system of Agilent 1100 series with UV detector at a wavelength of $275 \mathrm{~nm}$ was used. The mobile phase was water:methanol:2propanol (50:45:5, v:v:v) at $0.6 \mathrm{~mL} / \mathrm{min}$ flow rate. The column used was an ACE 5 C18 (25 cm x $4.6 \mathrm{~mm}$ i.d.) [8].

\subsection{Mineral analysis}

A microwave oven Anton PAAR Multiwave 3000 model were used for microwave-assisted digestion of plant materials. The mineral constituents in examined plant materials were analyzed by using Agilent 7500a ICP-MS.

\subsection{Determination of total phenolic and flavonoid content}

Powdered aerial parts (6 g) and seeds (0.75 g) were dispersed with $80 \%$ aqueous methanol sonicated for $60 \mathrm{~min}$ at $30{ }^{\circ} \mathrm{C}$. The supernatants were filtered through a Whatman Grade 1 filter paper. The volumes of the extract of seeds and aerial parts were adjusted to $100 \mathrm{~mL}$ and $25 \mathrm{~mL}$ by adding the appropriate volume of $80 \%$ aqueous methanol, respectively. The extracts were stored at $4{ }^{\circ} \mathrm{C}$ for the analysis [20]. The concentration of total phenolic contents was performed by the Folin-Ciocalteu method [21]. The total phenols were expressed in milligram equivalents of gallic acid (GAE) $(400-1000 \mathrm{mg} / \mathrm{L})$ per grams of sample. The amount of total flavonoids in the extracts was measured as the method described by Kim et al. (2003) with some modification based on that of the method described by Subhasree et al. [22]. The measurement was based on reaction with $\mathrm{AlCl}_{3}$ and spectrophotometric technique. All determinations were performed in triplicate. Results were expressed as $\mathrm{mg} / \mathrm{g}$ rutin equivalents (RE). The values are presented as means of triplicate analyses.

\subsection{DPPH radical-scavenging activity}

Radical scavenging activity of the extracts was determined as the method described by Yen and Duht (1994) [23]. Spectrophotometric analysis was used to measure the free radical scavenging capacity. The DPPH solution was prepared $6 \times 10^{-5} \mathrm{M}$ concentration. $0.1 \mathrm{~mL}$ of the each extract and standard solutions of butylated hydroxyanisole (BHA) (200$500 \mathrm{mg} / \mathrm{L}$ ) were added $2.9 \mathrm{~mL}$ the methanolic solution of DPPH. The mixtures were shaken vigorously and incubated in the dark for $45 \mathrm{~min}$ at room temperature and the decreases in the absorbance values were measured at $517 \mathrm{~nm}$ with a spectrophotometer [24]. All analysis was carried out in triplicate. The percentage of DPPH scavenging activity was calculated using the equation (1).

\% DPPH scavenging activity: $100\left(\mathrm{~A}_{\text {control }}\right.$ - $\left.\mathrm{A}_{\text {sample }} / \mathrm{A}_{\text {control }}\right)$

where $A_{\text {control }}$ is the absorbance of the control reaction mixture without the test compounds, and $\mathrm{A}_{\text {sample }}$ is the absorbance of the test compounds.

\section{Results and discussion}

The yield of the fixed oil from N. stellaris was 34.3\%. The fatty acid composition of the oil was presented in Table 1 . The oil was characterized by high amounts of unsaturated fatty acids. The most important fatty acids were linoleic and oleic acids which accounted for $71 \%$ of the total FAME. The oil contains $\mathrm{C}_{20: 2}$ eicosadienoic acid (4.9\%) that its presence was characterized to be a specific chemotaxonomic marker for Nigella species $[13,25]$. In this study, the total saturated fatty acids of the oil were $14.2 \%$. Palmitic acid was the main saturated fatty acid. In addition, total unsaturated fatty acids accounted for $79.1 \%$ of total fatty acids.

In literature, mainly $N$. sativa seed oil from different geographic origins was investigated for their fatty acid composition. N. sativa seeds contain a fixed oil (15.6-41.6\%) which is composed mainly unsaturated fatty acids including $\mathrm{C}_{20: 2}$ eicosadienoic acids $[6,9,19,25-28]$. The fatty acid composition of the other ten Nigella species has been investigated and the authors found that all the oils characterized by high amounts of unsaturated fatty acids [13]. 
Table 1. Fatty acid composition of $N$. stellaris seed oil.

\begin{tabular}{|c|c|}
\hline Fatty acid a & $\%^{\mathrm{b}}$ \\
\hline \multicolumn{2}{|l|}{ Saturated } \\
\hline $\mathrm{C}_{16: 0}$ (Palmitic acid) & $10.3 \pm 0.2$ \\
\hline $\mathrm{C}_{18: 0}$ (Stearic acid) & $3.7 \pm 0.2$ \\
\hline $\mathrm{C}_{20: 0}$ (Arachidic acid) & $0.2 \pm 0.1$ \\
\hline TSFA & $14.2 \pm 4.43$ \\
\hline \multicolumn{2}{|l|}{ Monounsaturated } \\
\hline $\mathrm{C}_{18: \ln 9}$ (Oleic acid) & $16.6 \pm 0.5$ \\
\hline $\mathrm{C}_{20: 1}$ (11-Eicosenoic acid) & $0.5 \pm 0.1$ \\
\hline TMUFA & $17.1 \pm 8.84$ \\
\hline \multicolumn{2}{|l|}{ Polyunsaturated } \\
\hline $\mathrm{C}_{18: 2 \mathrm{n} 6}$ (Linoleic acid) & $54.4 \pm 1.2$ \\
\hline $\mathrm{C}_{18: 3 \mathrm{n} 3}(\alpha$-Linolenic acid) & $0.3 \pm 0.1$ \\
\hline $\mathrm{C}_{18: 3 n 6}(\gamma$-Linolenic acid $)$ & $0.4 \pm 0.0$ \\
\hline $\mathrm{C}_{20: 2 \mathrm{n} 6}(11,14$-Eicosadienoic acid) & $4.9 \pm 1.3$ \\
\hline $\mathrm{C}_{20: 3 \mathrm{n} 3}(11,14,17$-Eicosatrienoic acid $)$ & $0.8 \pm 0.5$ \\
\hline $\mathrm{C}_{20: 4 n 6}$ (Arachidonic acid) & $0.6 \pm 0.1$ \\
\hline $\mathrm{C}_{22: 2}$ (Docosadienoic acid) & $0.6 \pm 0.4$ \\
\hline TPUFA & $62.0 \pm 19.13$ \\
\hline
\end{tabular}

b All values given are means of three determinations.

The present study shows that the qualitative composition of the oil from $N$. stellaris is in agreement with previously published data for fixed oils of Nigella seeds. This is the first report of composition of the oil from $N$. stellaris. The oil was rich in polyunsaturated fatty acids which play an important role in human health.

In this study, $N$. stellaris seeds were analyzed for their thymoquinone content by RP-HPLC in the methanolic extract. The seeds had a thymoquinone (TQ) concentration of $0.02 \pm 0.0003 \mu \mathrm{g} / \mathrm{mL}$. In the literature, the presence of TQ in essential/fixed oil and the methanolic extract of $N$. sativa seed were determined by different methods $[8,29]$. It was found that TQ content ranged between $3098.5-1274.6 \mathrm{mg} / \mathrm{kg}$ in the seeds from different origin [8]. It has been shown to be the principal active ingredient in the seeds of $N$. sativa [9]. To our knowledge this is the first report for TQ content in the seed of $N$. stellaris. The amount of pharmacologically active thymoquinone was lower than reported that of $N$. sativa seed in the literature.

The analyses of the oil showed that the oil contains two kinds of tocopherols which are $\alpha$-tocopherol and $\delta$-tocopherol. The oil contained $\alpha$-tocopherol $(2.04 \pm 0.07 \mathrm{mg} / 100 \mathrm{~g})$ and $\delta$ tocopherol $(0.17 \pm 0.01 \mathrm{mg} / 100 \mathrm{~g})$. Our results were quite different from the tocopherol composition of $N$. sativa seed oil that the oil had mainly $\alpha$ - and $\gamma$-tocopherols $[8,16]$.

The concentrations of twelve elements determined in $N$. stellaris seeds. Table 2 summarizes the element composition of examined seeds. The seeds contained significant amounts of important mineral elements. Phosphorus was relatively high in the seeds. Calcium and potassium were other predominant macrominerals among twelve elements analyzed in the seeds. The other important elements, in descending order by quantity, were $\mathrm{Mg}, \mathrm{Na}, \mathrm{Zn}, \mathrm{Mn}$ and Fe.

Table 2. Mineral content of $N$. stellaris seeds

\begin{tabular}{ll}
\hline Minerals & Content $(\mu \mathrm{g} / \mathrm{g}) *$ \\
\hline Macro minerals & \\
Calcium (Ca) & $4214 \pm 98$ \\
Magnesium (Mg) & $1612 \pm 49$ \\
Phosphorus (P) & $6913 \pm 117$ \\
Potassium (K) & $3637 \pm 99$ \\
Sodium (Na) & $427.90 \pm 13$ \\
Essential trace minerals & \\
Chromium (Cr) & $5.77 \pm 0.11$ \\
Copper (Cu) & $12.93 \pm 0.32$ \\
Iron (Fe) & $20.99 \pm 2.02$ \\
Manganese (Mn) & $21.16 \pm 1.3$ \\
Nickel (Ni) & $2.48 \pm 0.07$ \\
Selenium (Se) & $1.37 \pm 0.01$ \\
Zinc (Zn) & $58.93 \pm 3.41$ \\
\hline
\end{tabular}

*Values are means \pm standard deviations $(\mathrm{n}=3)$.

In the literature, mineral composition of $N$. sativa was studied extensively because of its using as a spice but there is no information about mineral content of $N$. stellaris as well as the other Nigella species [30,31]. N. stellaris seeds provide relatively high amounts of the minerals such as $\mathrm{P}, \mathrm{K}$ and $\mathrm{Ca}$ whereas $N$. sativa seeds are a source of $\mathrm{Ca}, \mathrm{Fe}$ and $\mathrm{K}$ [7].

The content of the total phenolic and flavonoids of the extracts from $N$. stellaris determined using Folin-Ciocalteu and $\mathrm{AlCl}_{3}$ spectrophotometrically method.

The seed extract of the plant had highest total phenolic content than the phenol content of the aerial parts (Table 3). The extracts of seeds and aerial parts of the flavonoid content was similar each other. Both extracts from the seeds showed high radical scavenging activity with DPPH radical. The flavonoid content exhibited a positive correlation with the antioxidant activity.

Table 3. Total phenolic and flavonoid content, and free radical scavenging activity of test samples from N.stellaris.

\begin{tabular}{llll}
\hline Sample & $\begin{array}{l}\text { Total phenolic } \\
\text { content } \\
\text { (mg of GAE/g) }\end{array}$ & $\begin{array}{l}\text { Total flavonoid } \\
\text { content } \\
\text { (mg of RE/g) }\end{array}$ & $\begin{array}{l}\text { Inhibition } \\
\text { (\%) }\end{array}$ \\
\hline Seed extract & $394.06 \pm 3.33$ & $130.24 \pm 0.04$ & $93.59 \pm 0.02$ \\
Aerial parts extract & $187.70 \pm 037$ & $92.58 \pm 0.02$ & $92.79 \pm 0.01$ \\
BHA $(0.5 \mathrm{mg} / \mathrm{mL})$ & - & - & $96.32 \pm 0.01$ \\
\hline
\end{tabular}

\section{Conclusions}

To our knowledge, we report fatty acid and mineral composition, tocopherol and thymoquinone, total phenol and flavonoid content for the first time from $N$. stellaris. In conclusion, N. stellaris seeds contain fixed oil which is rich sources of unsaturated fatty acids, minerals and phenols. The extracts have also strong antioxidant activity. Some further studies are necessary to the possibility of using $N$. stellaris seeds and the extracts as a potential source of nutraceuticals and to isolate the active constituents in the extract. Not only antioxidant activity but also other biological activity studies of the extracts from $N$. stellaris should be done to evaluate potential therapeutic uses of the plant.

\section{Acknowledgements}

This study was supported by the research fund of the University of Mersin (Project number: BAP-SBE-EMB (SS) 2008-6 YL). The authors thank Hamide Şenyuva and Dilek Çimen (Tübitak Ankara Test and Analysis Laboratory) for tocopherol and thymoquinone analysis and also thank to Deniz Yurtsever Sarıca (Tübitak Ankara Test and Analysis Laboratory) for mineral element analysis.

\section{References}

[1]. Hegnauer, R. Chemotaxonomie der Pflanzen, Birkhauser Verlag, Basel and Stutgart, 1973.

[2]. Davis, P. H. Flora of Turkey and the East Aegean Islands, Vol. 6, The Edinburgh University Press, Edinburgh, 1978.

[3]. Donmez, A. A.; Mutlu, B. Bot. J. Linn. Soc. 2004, 146, 251-255.

[4]. Burits, M.; Bucar, F. Phytother. Res. 2000, 14, 323-328.

[5]. Ali, B. H.; Blunden, G. Phytother. Res. 2003, 17, 299-305.

[6]. Khan, M. A. Inflammopharmacology 1999, 7(1), 15-35.

[7]. Salem, M. L. Int. Immunopharm. 2005, 5, 1749-1770.

[8]. Al-Saleh, I. A.; Billedo, G.; El-Doush, I. I. J. Food Compos. Anal. 2006, 19, 167-175.

[9]. Ramadan, M. F. Int. J. Food Sci. Tech. 2007, 42, 1208-1218.

[10]. Abdel-Fattah, A. M.; Matsumoto, K.; Watanabe, H. Eur. J. Pharmacol. 2000, 400, 89-97.

[11]. Hosseinzadeh, H.; Parvardeh, S. Phytomedicine 2004, 11, 56-64

[12]. Kanter, M. Neurochem. Res. 2008, 33, 579-588.

[13]. Kökdil, G.; Yılmaz, H. Biochem. Syst. Ecol. 2005, 33, 1203-1209.

[14]. Kökdil, G.; Tamer, L.; Ercan, B.; İlçim, A.; Aras, N.; Atik, U. J. Ethnopharmacol. 2005, 99, 131-135.

[15]. Gharibzahedi, S. M. T.; Mousavi, S. M.; Jouki, M.; Ghahderijani, M. Int. J. Food Eng. 2012, 8(3), 1556-3758.

[16]. Matthaus, B.; Ozcan, M. M. Czech J. Food Sci. 2011, 29(2), 145-150.

[17]. Javorka, V.; Vaclavic, J.; Kubinova, R.; Muselik, J. Acta Fytotechnica Et Zootechnica 2011, 14, 1-4.

[18]. Davis, P. H. Flora of Turkey and the East Aegean Islands, Vol. 10, The Edinburgh University Press, Edinburgh, 1988. 
[19]. Houghton, P. J.; Zarka, R.; Heras, B.; Hoult, R. S. Planta Med. 1995, 61, 33-36.

[20]. Gikas, E.; Bazoti, F. N.; Papadopoulos, N.; Alesta, A.; Economou, G.; Tsarbopoulos, A. Anal. Lett. 2011, 44, 1463-1472.

[21]. Kim, D. O.; Jeong, S. W.; Lee, C. Y. Food Chem. 2003, 81, 321-326.

[22]. Subhasree, B.; Baskar, R.; Keerthana, R. L.; Susan, R. L.; Rajasekaran, P. Food Chem. 2009, 115, 1213-1220.

[23]. Yen, G. C.; Duht, P. D. J. Agr. Food Chem. 1994, 42, 629-632.

[24]. Gungor, S. S. U.; Ozay, S. G.; Ilcim, A.; Kokdil, G. Eur. J. Chem. 2013, 4(1), 7-9.

[25]. Aitzetmüller, K.; Werner, G. OCL-Oleagineux Corps Gras Lipides 1997, 4, 385-388.

[26]. Al-Jassir, M. S. Food Chem. 1992, 45, 239-242.

[27]. Nergiz, C.; Otleș, S. Food Chem. 1993, 48, 259-261.

[28]. Atta, M. B. Food Chem. 2003, 83, 63-68.

[29]. Michelitsch, A.; Rittmannsberger, A. Phytochem. Anal. 2003, 14, 224227.

[30]. Gupta, K. K.; Bhattacharjee, S.; Kar, S.; Chakrabarty, S.; Thakur, P.; Bhattacharyya, G.; Srivastava, S. C. Commun. Soil Sci. Plan. 2003, 34, 681-693.

[31]. Jasim, N. A.; Abid, F. Iraqi Nat. J. Chem. 2011, 42, 178-184. 